\title{
Effect of silencing colon cancer-associated transcript 2 on the proliferation, apoptosis and autophagy of gastric cancer BGC-823 cells
}

\author{
ZHAO-YAN YU ${ }^{1}$, ZI WANG ${ }^{2}$, KE-YUE LEE ${ }^{3}$, PING YUAN $^{1}$ and JIE DING $^{1}$ \\ Departments of ${ }^{1}$ General Surgery, ${ }^{2}$ Oncology and ${ }^{3}$ Hepatobiliary Surgery, \\ Guizhou Provincial People's Hospital, Guiyang, Guizhou 550002, P.R. China
}

Received February 25, 2017; Accepted October 26, 2017

DOI: $10.3892 / \mathrm{ol} .2017 .7677$

\begin{abstract}
The role of long non-coding RNAs (lncRNAs) in the carcinogenesis and progression of tumors has been receiving increasing attention. Colon cancer-associated transcript 2 (CCAT2), a type of oncogenic lncRNA, is regarded as a novel biomarker of poor prognosis and metastasis in various types of cancer. However, the molecular contributions of CCAT2 to gastric cancer (GC) progression remain largely unclear. The aim of the present study was to demonstrate the effect of silencing CCAT2 on the biological behavior of GC BGC-823 cells and illustrate the potential underlying molecular mechanisms. A short hairpin RNA interference plasmid pRNAT-U6.1-CCAT2 targeting CCAT2 was successfully constructed. At $48 \mathrm{~h}$ after transfection with the interference plasmid, the survival rate of BGC-823 cells was significantly decreased, as determined by the MTT assay. In addition, RT-qPCR results revealed that CCAT2 gene expression was effectively suppressed by the transfection, while POU domain class 5 transcription factor 1B (POU5F1B) gene expression was significantly decreased. Terminal deoxynucleotidyl transferase dUTP nick end labeling assay further revealed that the apoptotic index was significantly higher in the interference group. Western blot analysis also demonstrated that the expression of beclin-1 protein was significantly increased, whereas the expression levels of phosphoinositide 3-kinase (PI3K) and mammalian target of rapamycin (mTOR) proteins were downregulated in the interference group. In conclusion, CCAT2 was able to positively regulate the expression of POU5F1B gene. Furthermore, silencing of CCAT2 gene inhibited the proliferation of BGC-823 cells, as well as induced apoptosis and autophagy in
\end{abstract}

Correspondence to: Mr. Jie Ding, Department of General Surgery, Guizhou Provincial People's Hospital, 83 East Zhongshan Road, Guiyang, Guizhou 550002, P.R. China

E-mail: djofgzsy@163.com

Key words: gastric cancer, long non-coding RNA, colon cancer-associated transcript 2, POU domain class 5 transcription factor $1 \mathrm{~B}$, apoptosis, autophagy
BGC-823 cells, by suppression of the PI3K/mTOR signaling pathways.

\section{Introduction}

Gastric cancer (GC) is currently the fourth most common cancer and the second most common cause of cancer-associated mortality worldwide (1). In spite of the continuous development of novel treatment options for GC, the prognosis of this disease remains generally poor. The carcinogenesis and progression of GC are complicated processes, among which the detailed molecular mechanisms have not been elaborated thus far. The role of long non-coding RNAs (lncRNAs) in the carcinogenesis and progression of tumors has been receiving increasing attention. IncRNAs, a type of non-coding RNA of $>200$ nucleotides, lack an open reading frame and are unable to encode proteins; however, they are involved in the regulation of cellular development, proliferation, differentiation and apoptosis (2). The dysregulation of lncRNAs has been confirmed to be associated with tumor initiation, progression, invasion and metastasis in various types of cancer (3). Therefore, comprehensive investigation of the lncRNA function will provide a novel insight into the diagnosis, prognosis and targeted therapy for cancer.

Colon cancer-associated transcript 2 (CCAT2), a novel lncRNA first identified by Ling et al (4), encompasses the rs6983267 single nucleotide polymorphism (SNP) and is highly overexpressed in microsatellite-stable colorectal cancer. A meta-analysis demonstrated that high expression of CCAT2 may serve as a novel biomarker of poor prognosis and metastasis in various cancer types (5). Two previous experimental studies examining the association of CCAT2 and GC confirmed that a high expression of CCAT2 was closely associated with a higher incidence of lymph node and distant metastases, as well as shorter overall and progression-free survival rates $(6,7)$. However, the molecular contributions of CCAT2 to GC progression remain largely unclear.

In the present study, it was attempted to illustrate the function of CCAT2 by the construction of an interference short hairpin RNA (shRNA) plasmid targeting CCAT2. In addition, the effect of this plasmid on the proliferation, apoptosis and autophagy of GC cells, as well as the potential underlying molecular mechanisms, were investigated. 


\section{Materials and methods}

Construction of shRNA plasmid targeting CCAT2. An interference sequence was designed according to the sequence of CCAT2 in GenBank (NC_000008.11), and Basic Local Alignment Search Tool Analysis (blast.ncbi.nlm.nih.gov/ Blast.cgi) indicated no homology with other genes. shRNA was synthesized by two complementary oligonucleotide strands, as follows: 5'-CGCGGGATCCCGGTGCAACTCTGCAATTTA ATTTTCAAGAGAAATTAAATTGCAGAGTTGCACTTTTT TCCAAAAGCTTAA-3' (sense) and 5'-AACTTAAGCTTT TGGAAAAAAGTGCAACTCTGCAATTTAATTTCTCTT GAAAATTAAATTGCAGAGTTGCACCGGGATCCC-3' (antisense). Double-stranded oligonucleotides (ds-oligo) of shRNA were obtained subsequent to annealing at $95^{\circ} \mathrm{C}$ for $5 \mathrm{~min}$. Plasmid pRNAT-U6.1 (GenScript, Jiangsu, China) and shRNA ds-oligo were digested using the enzymes BamHI and HindIII (Takara Biotechnology Co., Ltd., Dalian, China) simultaneously in a water bath of $37^{\circ} \mathrm{C}$ for $30 \mathrm{~min}$. The reaction system of dual enzyme digestion included $1 \mu \mathrm{l}$ BamHI, $1 \mu \mathrm{l}$ HindIII, $2 \mu 1$ 10X K buffer, $5 \mu 1$ pRNAT-U6.1 plasmid or shRNA ds-oligo, and $11 \mu \mathrm{lddH_{2 }} \mathrm{O}$. DNA was purified and recovered according to the instructions of the DNA gel extraction kit (Tiangen Biotech Co., Ltd., Beijing, China). Next, T4 DNA ligase (NEB, Beijing, China) was used to clone the shRNA ds-oligo into the linear plasmid pRNAT-U6.1, and the reaction system of DNA directional ligation was built following the manufacturer's protocol. The products were transformed into Trans $5 \alpha$ competent cells (Tiangen Biotech Co., Ltd.), and then monoclonal clones were identified with polymerase chain reaction (PCR) and enzyme digestion. Briefly, Luria-Bertani bacterial liquid medium was added to the 96-well plate $(200 \mu \mathrm{l}$ / well). Monoclonal transformants were randomly selected in the bacterial culture plate and added to the wells of 96-well plate with sterile toothpicks. Following incubation in a bacterial incubator for $1 \mathrm{~h}$ at $37^{\circ} \mathrm{C}$, the bacterial liquid was used for PCR identification. Reaction system of PCR included $10 \mu 12 \mathrm{X}$ Taq Master Mix (Lifefeng Biotechnology Co., Ltd., Shanghai, China), $2 \mu \mathrm{l} 10 \mu \mathrm{M}$ primer mixture, $1 \mu \mathrm{l}$ bacteria liquid, and $7 \mu \mathrm{ldd} \mathrm{d}_{2} \mathrm{O}$. The following primers were used: The following primers for PCR identification were used: forward, 5'-GGA TCCCGGT GCAACTCTG-3' and reverse, 5'-AAGGCACAG TCGAGGC TGAT-3' (Chongqing Western Biological Medicine Science and Technology Co., Ltd., Chongqing, China). PCR reaction conditions were as follows: $95^{\circ} \mathrm{C}$ for $5 \mathrm{~min} ; 94^{\circ} \mathrm{C}$ for $30 \mathrm{sec}, 60^{\circ} \mathrm{C}$ for $30 \mathrm{sec}, 72^{\circ} \mathrm{C}$ for $10 \mathrm{~min}, 30$ cycles. The PCR products were analyzed using $1 \%$ agarose gel electrophoresis. Positive clones were considered when there were DNA bands. The steps of enzyme digestion were the same as those methods mentioned above, and the products were added to $1 \%$ agarose gel electrophoresis. Positive clones were considered when there were DNA fragments 69 bp long. The positive clone was further sequenced to identify the successfully constructed recombinant pRNAT-U6.1-CCAT2.

Cell culture and transfection. The human BGC-823 cell line was purchased from the Type Culture Collection of the Chinese Academy of Sciences (Beijing, China). The cells were cultured in RPMI-1640 medium (Gibco; Thermo Fisher Scientific, Inc., Waltham, MA, USA) supplemented with $10 \%$ fetal bovine serum (Gibco; Thermo Fisher Scientific, Inc.), $2 \mathrm{mM}$ glutamine, $100 \mathrm{U} / \mathrm{ml}$ penicillin and $100 \mu \mathrm{g} / \mathrm{ml}$ streptomycin, and maintained at $37^{\circ} \mathrm{C}$ in an atmosphere of $95 \% \mathrm{O}_{2}$ and $5 \% \mathrm{CO}_{2}$. The experimental groups were as follows: i) Blank control (BC) group, untransfected BGC-823 cells; ii) negative control (NC) group, BGC-823 cells transfected with the empty pRNAT-U6.1 plasmid; and iii) interference group, BGC-823 cells transfected with the pRNAT-U6.1-CCAT2 plasmid. Prior to transfection, BGC-823 cells $\left(1 \times 10^{5} / \mathrm{ml}\right)$ were grown in 24 -well plates until $70-80 \%$ confluence was reached. Cell transfection was performed using Lipofectamine ${ }^{\circledR} 2000$ (Invitrogen; Thermo Fisher Scientific, Inc.) according to the manufacturer's instructions. Briefly, $2 \mu \mathrm{l} /$ well Lipofectamine ${ }^{\circledR} 2000$ or $0.8 \mu \mathrm{g}$ vector DNA was diluted to a final volume of $50 \mu \mathrm{l}$ using Opti-MEM medium (Invitrogen; Thermo Fisher Scientific, Inc.), respectively. The diluent of vector DNA was added to Lipofectamine ${ }^{\circledR} 2000$, and then the mixture were incubated for $20 \mathrm{~min}$ at room temperature. The culture medium was removed from the plate, and then the transfection complex was added. Following incubation for 4-6 h at $37^{\circ} \mathrm{C}$, fresh medium was used for further cell culturing.

Cell proliferation assays. BGC-823 cells in the logarithmic growth phase were counted to adjust the cell concentration to $1 \times 10^{5} / \mathrm{ml}$. Next, the cells were seeded into 96 -well plates with $100 \mu \mathrm{l} /$ well, transfected with the plasmid based on the experimental grouping and then cultured for 12,24 and $48 \mathrm{~h}$. Triplicate wells were used for each group. The cell proliferation was assessed using an MTT Cell Proliferation Reagent kit (Beyotime Institute of Biotechnology, Jiangsu, China) following the manufacturer's instructions. Briefly, $10 \mu \mathrm{l}$ MTT (5 g/l) was added to each well subsequent to culture for 12,24 or $48 \mathrm{~h}$, and the cells were maintained in the culture medium for $4 \mathrm{~h}$. Next, $150 \mu \mathrm{l}$ dimethyl sulfoxide per well was added following the removal of the culture medium. The 96-well plate was then placed in an oscillator for low speed oscillation for $10 \mathrm{~min}$. Subsequently, the absorbance of each well at $490 \mathrm{~nm}$ was detected using a microplate reader, and the cell survival was calculated as follows: Cell survival rate $(\%)=($ absorbance of experimental group $) /($ absorbance of untransfected blank control group) x $100 \%$.

Reverse transcription-quantitative PCR (RT-qPCR) assay. BGC-823 cells were harvested at $48 \mathrm{~h}$ after transfection. Total RNA was isolated from the cultured cells using TRIzol ${ }^{\circledR}$ reagent (Shinegene Molecular Biotech, Inc., Shanghai, China). RT of total RNA into first-strand cDNA and qPCR analysis were performed using RT kit (Chongqing Western Biological Medicine Science and Technology Co., Ltd., Chongqing, China) and Shinegene Real Time PCR Core kit (Shinegene Molecular Biotech, Inc.), respectively, according to the manufacturer's instructions.

The reaction system of RT assay included $10 \mu \mathrm{l} 2 \mathrm{X} \mathrm{RT}$ buffer, $1 \mu \mathrm{l} 6 \mathrm{~N}$ random primer (100 pmol $/ \mu \mathrm{l}), 1 \mu \mathrm{l}$ RT-Mix, $5 \mu \mathrm{l}$ RNA and $3 \mu \mathrm{l}$ RNase-free $\mathrm{ddH}_{2} \mathrm{O}$. The RT reaction was conducted at $25^{\circ} \mathrm{C}$ for $10 \mathrm{~min}, 42^{\circ} \mathrm{C}$ for $50 \mathrm{~min}$ and then $85^{\circ} \mathrm{C}$ for $5 \mathrm{~min}$. Subsequently, qPCR was performed in a $50 \mu \mathrm{l}$ reaction system containing $25 \mu 12 \mathrm{X}$ PCR buffer, $1 \mu$ l each primer (25 pmol $/ \mu \mathrm{l}$ ), $0.5 \mu \mathrm{l}$ SYBR Green I (Shinegene Real Time PCR Core kit; Shinegene), $2 \mu 1 \mathrm{cDNA}$ and $20.5 \mu \mathrm{l}$ RNase-free $\mathrm{ddH}_{2} \mathrm{O}$. The house keeping gene $\beta$-actin mRNA was used to 
normalize the level of cDNA. The following primers were used in the qPCR assay: CCAT2 forward, 5'-AAGAGGAAA CCACCTTGGACTG-3' and reverse, 5'-GCAATAAGAGCA GGAAAAGAAGC-3'; POU domain class 5 transcription factor 1B (POU5F1B) forward, 5'-GCGATCAAGCAGCGA CTATG-3' and reverse, 5'-CAGGGAAAGGGACTGAGG AG-3'; and $\beta$-actin forward, 5'-TGACGTGGACATCCGCAA AG-3' and reverse, 5'-CTGGAAGGTGGACAGCGAGG-3'. The qPCR reaction conditions were as follows: $94^{\circ} \mathrm{C}$ for $4 \mathrm{~min}$, followed by 35 cycles of amplification at $94^{\circ} \mathrm{C}$ for $20 \mathrm{sec}, 60^{\circ} \mathrm{C}$ for $15 \mathrm{sec}$ and $72^{\circ} \mathrm{C}$ for $30 \mathrm{sec}$. All samples were amplified in triplicates. The results were evaluated with the Bio-Rad CFX Manager software (version 3.1; Bio-Rad Laboratories, Inc., Hercules, CA, USA). The quantification cycle (Cq) value was read, and the relative expression of target gene was calculated according to the $2^{-\Delta \Delta \mathrm{Cq}}$ method (8).

Terminal deoxynucleotidyl transferase dUTP nick end labeling (TUNEL) assay. BGC-823 cells were seeded in the 6-well plates containing sterile coverslips, and cultured $48 \mathrm{~h}$ after plasmid transfection. Subsequent to fixing using $4 \%$ paraformaldehyde for $30 \mathrm{~min}$, apoptotic cells were detected with an In Situ Cell Apoptosis Detection kit (Boster Biological Technology, Pleasanton, CA, USA) according to the method described by Zhao et al (9). Apoptotic cells exhibited positive staining (pale brown) in cell nucleus. Five high power fields of each slide at a magnification of $x 400$ were randomly examined under a light microscope to determine the percentage of apoptotic cells (expressed as the apoptotic index) among at least 500 cells.

Western blot analysis. The culture medium of BGC-823 cells was discarded $48 \mathrm{~h}$ after transfection. Cells were then lysed and total proteins were extracted using a radioimmunoprecipitation assay protein extraction reagent (Beyotime Institute of Biotechnology). Next, the protein concentration was quantified using a bicinchoninic acid protein assay kit (Beyotime Institute of Biotechnology). Equal amounts $(20 \mu \mathrm{g})$ of protein extracts were separated by $10 \%$ SDS-PAGE, and then transferred to polyvinylidene fluoride membranes (Bio-Rad Laboratories, Inc.). Subsequent to blocking with 5\% skim-milk for $2 \mathrm{~h}$ at room temperature, the membranes were incubated with rabbit polyclonal antibodies against beclin-1 (1:500; cat. no. ab62557), mammalian target of rapamycin (mTOR; 1:50; cat. no. ab2732), phosphoinositide 3-kinase (PI3K; 1:500; cat. no. ab151549) and $\beta$-actin $(1: 1,000$; cat. no. ab8227; all from Abcam, Cambridge, UK) at $4^{\circ} \mathrm{C}$ overnight. The membranes were then washed in Tris-buffered saline/Tween-20 and incubated with goat anti-rabbit immunoglobulin G (1:1,000; cat. no. A0545; Sigma-Aldrich; Merck KGaA, Darmstadt, Germany) for $2 \mathrm{~h}$ at $37^{\circ} \mathrm{C}$. Protein bands were visualized using the BeyoECL Plus reagent (Beyotime Institute of Biotechnology), and the fluorescence intensity was quantified using the ImageJ v.2.1.4.7 software (National Institutes of Health, Bethesda, MD, USA).

Statistical analysis. All data are presented as the mean \pm standard deviation. Differences among groups were tested by one-way analysis of variance, followed by Student-Newman-Keuls test. Statistical analyses were performed using SPSS v.22.0 software (IBM Corp., Armonk, NY, USA). P $<0.05$ was considered to indicate a statistically significant difference. Graphs were

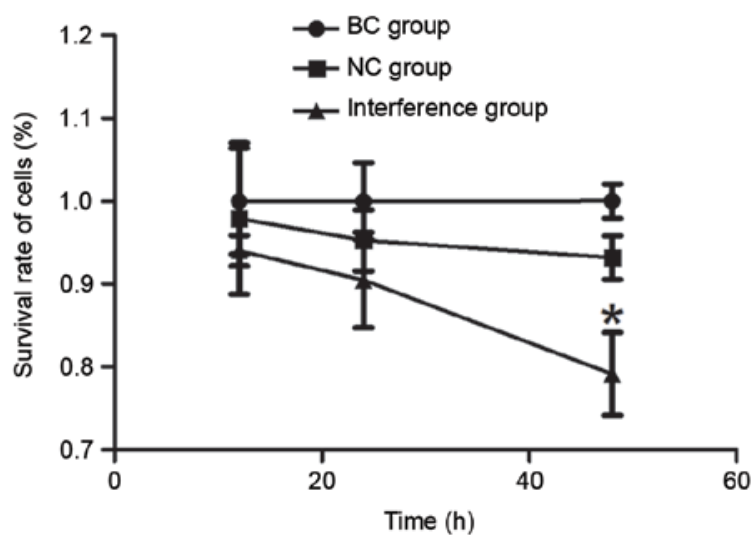

Figure 1. Survival rate of BGC- 823 cells in each group at three time-points $(12,24$ and $48 \mathrm{~h})$. The survival rate was only $79.15 \%$ at $48 \mathrm{~h}$ in the interference group transfected with the pRNAT-U6.1-CCAT2 plasmid. ${ }^{*} \mathrm{P}<0.05$ vs. the BC and NC groups. CCAT2, colon cancer-associated transcript 2; $\mathrm{BC}$, blank control; NC, negative control.

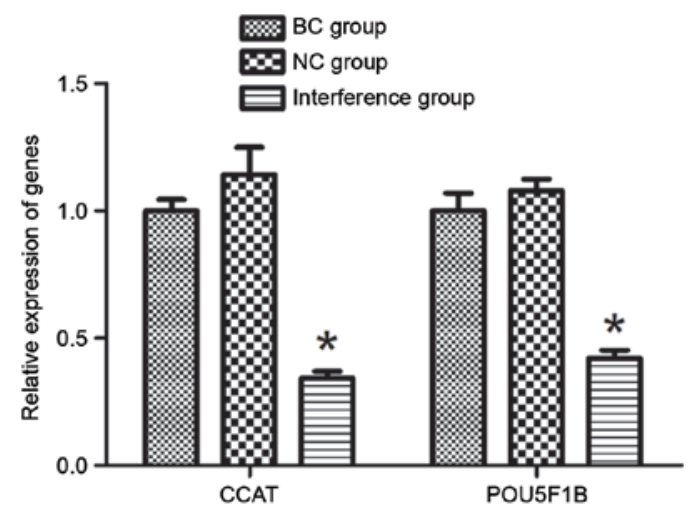

Figure 2. Relative expression levels of the CCAT2 and POU5F1B genes in BGC-823 cells at $48 \mathrm{~h}$ in each group, as determined using reverse transcription-quantitative polymerase chain reaction. The expression levels of the CCAT2 and POU5F1B genes in the interference group that was transfected with the pRNAT-U6.1-CCAT2 plasmid were downregulated by 0.34 - and 0.42 -fold, respectively, compared with the $\mathrm{BC}$ group. ${ }^{*} \mathrm{P}<0.05$ vs. BC and NC groups. CCAT2, colon cancer-associated transcript 2; POU5F1B, POU domain class 5 transcription factor 1B; BC, blank control; $\mathrm{NC}$, negative control.

constructed with GraphPad Prism 5.0 software (GraphPad Software, Inc., La Jolla, CA, USA).

\section{Results}

Construction of pRNAT-U6.1-CCAT2 interference plasmid. In the present study, a recombinant shRNA interference plasmid was constructed to investigate the function of CCAT2 gene in GC cells. The positive clones were sequenced and compared with target DNA sequencing, and the results demonstrated that the inserted DNA fragment was identical to the expected CCAT2 interference sequence, suggesting that the interference plasmid pRNAT-U6.1-CCAT2 was successfully constructed.

MTT assay for determination of the cell viability. The viability of the GC cells was determined at three time-points, namely 12, 24 and 48 h, using an MTT assay. As observed in Fig. 1, the survival rate of BGC-823 cells gradually declined with 

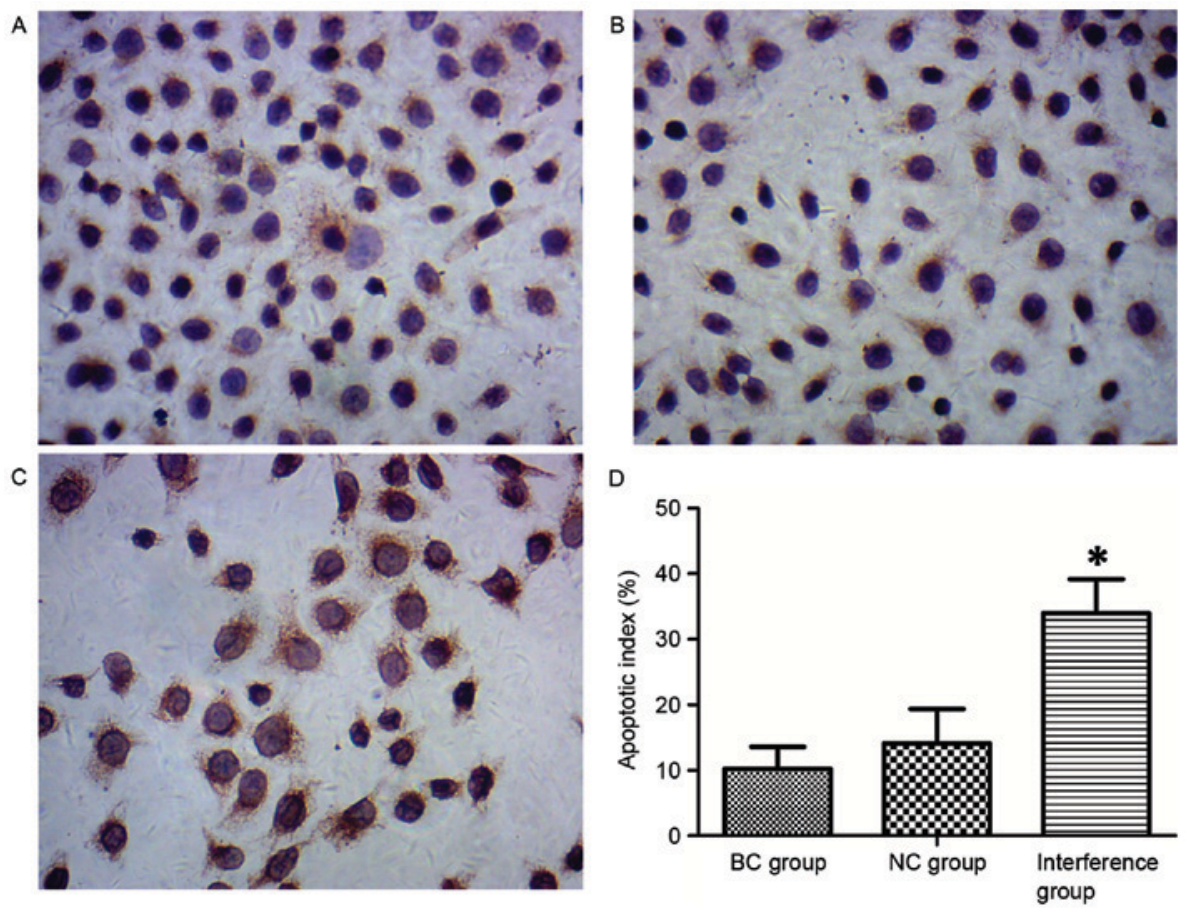

Figure 3. Detection of BGC-823 cell apoptosis at $48 \mathrm{~h}$ in each group using TUNEL assay. TUNEL staining of the BGC-823 apoptotic cells are presented for the (A) BC, (B) NC and (C) interference groups (magnification, x400). (D) Histogram results demonstrated the difference of apoptotic index between three groups. "P<0.05 vs. BC and NC groups. TUNEL, terminal deoxynucleotidyl transferase dUTP nick end labeling; BC, blank control; NC, negative control.

the increase in culture time following transfection with the pRNAT-U6.1-CCAT2 plasmid. The lowest cell viability was observed at $48 \mathrm{~h}$, with a statistically significant difference observed at this time-point when compared with the $\mathrm{BC}$ and $\mathrm{NC}$ groups $(\mathrm{P}<0.05)$.

RT-qPCR detection of CCAT2 and POU5F1B gene expression levels. To confirm the effect of pRNAT-U6.1-CCAT2 plasmid on the gene expression levels of CCAT2 and POU5F1B in BGC-823 cells, RT-qPCR detection was performed. As presented in Fig. 2, the RT-qPCR results demonstrated that the relative expression of CCAT2 in the interference group decreased significantly as compared with that of the $\mathrm{BC}$ and $\mathrm{NC}$ groups $(\mathrm{P}<0.05)$, whereas no significant difference in CCAT2 expression was observed between the $\mathrm{BC}$ and $\mathrm{NC}$ groups, indicating that the pRNAT-U6.1-CCAT2 plasmid was able to silence the function of the CCAT2 gene in BGC-823 cells. Along with the decrease in the expression of CCAT2 in the plasmid-transfected BGC-823 cells, the relative expression of POU5F1B gene was also downregulated in the interference group, with a significant difference detected compared with the $\mathrm{BC}$ and $\mathrm{NC}$ groups ( $\mathrm{P}<0.05$; Fig. 2).

TUNEL detection of cell apoptosis. TUNEL staining identified that typical apoptotic features were observed in the BGC-823 cells, with numerous brown granules products in the nucleus of apoptotic cells (Fig. 3A-C). The TUNEL results revealed that the apoptotic index of BGC- 823 cells in the interference group $(33.98 \pm 5.22 \%)$ was significantly higher as compared with that in the $\mathrm{BC}$ and $\mathrm{NC}$ groups $(10.23 \pm 3.34$ and $14.12 \pm 5.23 \%$, respectively; $\mathrm{P}<0.05$; Fig. 3D).

Western blot detection of protein expression. The autophagy-associated protein beclin-1 and the PI3K/mTOR
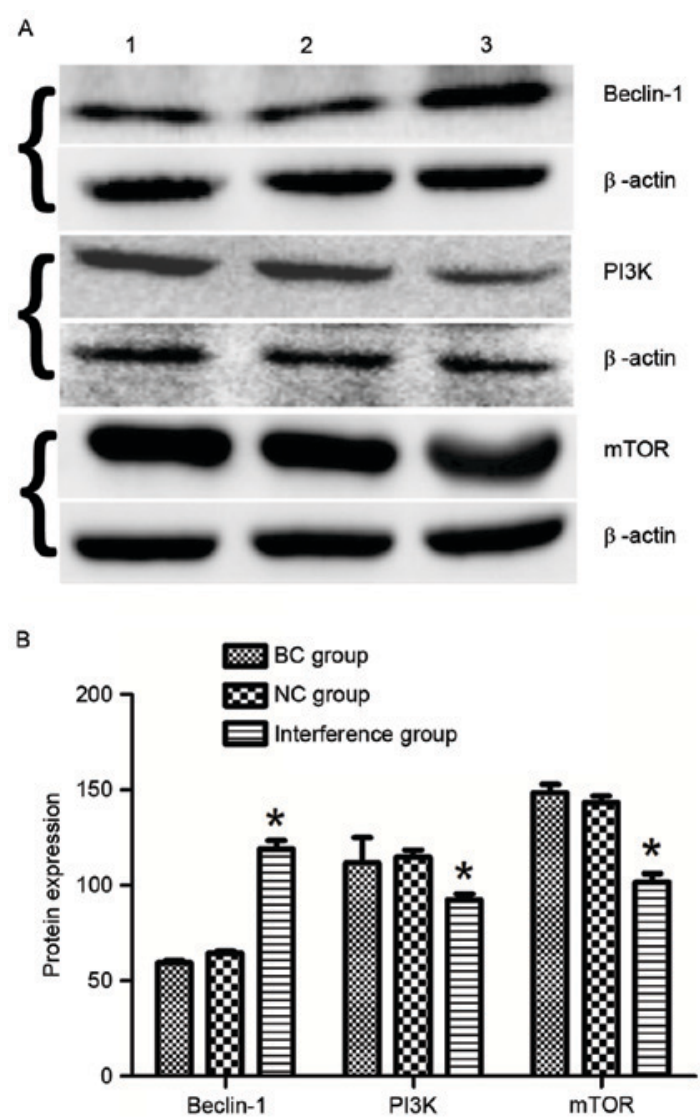

Figure 4. Detection of protein expression levels of Beclin-1, PI3K and mTOR of BGC-823 cells at $48 \mathrm{~h}$ in each group using western blot analysis. (A) Protein bands are demonstrated for the $\mathrm{BC}, \mathrm{NC}$ and interference groups. $\beta$-actin was used as an internal reference. (B) Quantified results demonstrate the difference in the relative protein expression levels among the three groups. ${ }^{*} \mathrm{P}<0.05$ vs. the BC and NC groups. PI3K, phosphoinositide 3-kinase; mTOR, mammalian target of rapamycin; $\mathrm{BC}$, blank control; $\mathrm{NC}$, negative control. 
signaling pathway proteins in BGC-823 cells at $48 \mathrm{~h}$ after transfection with the plasmids were detected using western blot assay. The results demonstrated that BGC-823 cells in the interference group exhibited a significantly increased expression of beclin-1 protein (1.99- and 1.81-fold increase vs. the $\mathrm{BC}$ and $\mathrm{NC}$ groups, respectively; $\mathrm{P}<0.05$; Fig. 4). Furthermore, the expression levels of PI3K and mTOR proteins in the interference group were downregulated by 0.78 - and 0.69 -fold compared with those in the $\mathrm{BC}$ and $\mathrm{NC}$ groups $(\mathrm{P}<0.05)$.

\section{Discussion}

lncRNAs function as oncogenes or tumor suppressors during the occurrence and development of GC. Several lncRNAs, including LINC00152, GHET1, HULC, HOTAIR, GACAT3, MALAT2 and H19, have been demonstrated to serve as oncogenes, whereas other lncRNAs, including LEIGC, GAS5 and FER1L4, have been considered to be tumor suppressors (10). Emerging evidence indicated that CCAT2 functions as a cancer-promoting molecule in several types of solid cancer, such as in non-small cell lung cancer (11), oral squamous cell carcinoma (12), ovarian cancer (13), and hepatocellular carcinoma (14). The present study investigated the effects of the lncRNA CCAT2 on the biological behavior of BGC-823 cells, and revealed that knockdown of CCAT2 expression effectively inhibited the proliferation, as well as induced the apoptosis and autophagy of GC cells in vitro. These effects may be derived from the downregulation of the expression of POU5F1B gene as a result of silencing CCAT2.

Recent studies confirmed that the IncRNA CCAT2, located at the 8q24 amplicon of the cancer risk-associated rs6983267 SNP, regulated the cancer metabolism in vitro and in vivo by directly interacting in an allele-specific manner with a protein complex $(15,16)$. The chromosomal region 8q24 emerged as an important region for genetic susceptibility in various cancer types, thus DNA methylation or SNPs at this locus may contribute to cancer risk $(17,18)$. The retrogene POU5F1B has been observed to be located adjacent to the MYC gene within this risk locus at chromosome 8q24 (19). POU5F1B has a preserved open reading frame encoding a homolog of the master embryonic stem cell transcription factor POU5F1, also known as octamer-binding transcription factor 4. A study revealed that the expression of POU5F1B was upregulated in GC cell lines and tissues, while POU5F1B also exhibited mitogenic, angiogenic and antiapoptotic effects in vivo (20). In the present study, it was observed that the expression of POU5F1B was downregulated along with the decreased expression of CCAT2 in BGC-823 cells transfected with the CCAT2-silencing plasmid, which suggested that CCAT2 positively regulated the expression of POU5F1B gene to a certain extent. Therefore, the POU5F1B gene may be one of the downstream target genes of CCAT2.

As the two main forms of programmed cell death, autophagy and apoptosis induce the degradation of proteins and organelles, or cell death upon cellular stress (21). Autophagy is associated with both the tumorigenic and protective effects in cancer; however, the role of autophagy in GC remains unclear (22). During the autophagic process, the autophagy-associated markers beclin-1 (which is the mammalian homologue of yeast Atg6) serves not only as a key autophagy regulator with its specific interactors, but also as a potential therapeutic target in cancer (23). A meta-analysis revealed that the expression of beclin-1 in GC tissues was significantly reduced when compared with that in non-GC tissues, and the upregulated expression of beclin-1 was associated with marked differentiation of tumor cells, no distant metastasis and a favorable overall survival of GC (24-26). Furthermore, there are close interactions between autophagy and apoptosis through shared signaling pathways, among which the PI3K/protein kinase B $(\mathrm{AKT}) / \mathrm{mTOR}$ is a crucial intracellular signaling pathway in tumorigenesis (27). Liu et al (28) demonstrated that celecoxib may impact apoptosis and autophagy via the PI3K/AKT signaling pathway in the SGC-7901 GC cells. Therefore, the $\mathrm{PI} 3 \mathrm{~K} / \mathrm{AKT} / \mathrm{mTOR}$ signaling pathway serves a critical role in the regulation of apoptosis and autophagy. In the present study, the data revealed that silencing of the CCAT2 gene induced upregulation of the apoptosis and autophagy of GC cells by downregulating the expression levels of PI3K and mTOR proteins.

In conclusion, the present study constructed a CCAT2 interference plasmid, and further examined the effect of CCAT2 on the biological behavior of GC cells and its possible underlying molecular mechanism. However, the specific regulatory mechanisms require further investigation.

\section{Acknowledgements}

This study was supported by grants from the Guizhou Provincial Fund Project of Science and Technology [grant no. (2015)2095], the Science and Technology Fund Projects of Guizhou Provincial Health and Family Planning Commission (grant no. gzwjkj2015-1-019), and the Joint Fund Project of Guizhou Provincial Science and Technology Agency [grant no. (2015)7170].

\section{References}

1. Brenner H, Rothenbacher D and Arndt V: Epidemiology of stomach cancer. Methods Mol Biol 472: 467-477, 2009.

2. Zhang $M$ and Du X: Noncoding RNAs in gastric cancer: Research progress and prospects. World J Gastroenterol 22: 6610-6618, 2016.

3. Zhang R, Xia LQ, Lu WW, Zhang J and Zhu JS: LncRNAs and cancer. Oncol Lett 12: 1233-1239, 2016.

4. Ling H, Spizzo R, Atlasi Y, Nicoloso M, Shimizu M, Redis RS, Nishida N, Gafà R, Song J, Guo Z, et al: CCAT2, a novel noncoding RNA mapping to 8q24, underlies metastatic progression and chromosomal instability in colon cancer. Genome Res 23: 1446-1461, 2013.

5. Fan YH, Fang H, Ji CX, Xie H, Xiao B and Zhu XG: Long noncoding RNA CCAT2 can predict metastasis and poor prognosis: A meta-analysis. Clin Chim Acta 466: 120-126, 2017.

6. Wang CY, Hua L, Yao KH, Chen JT, Zhang JJ and Hu JH: Long non-coding RNA CCAT2 is up-regulated in gastric cancer and associated with poor prognosis. Int J Clin Exp Pathol 8: 779-785, 2015.

7. Wang YJ, Liu JZ, Lv P, Dang Y, Gao JY and Wang Y: Long non-coding RNA CCAT2 promotes gastric cancer proliferation and invasion by regulating the E-cadherin and LATS2. Am J Cancer Res 6: 2651-2660, 2016.

8. Livak KJ and Schmittgen TD: Analysis of relative gene expression data using real-time quantitative PCR and the 2(-Delta Delta C(T)) method. Methods 25: 402-408, 2001.

9. Zhao X, Ma C, Cai X, Lei D, Liu D, Xu F, Jin T, Liu J and Pan X: RNA interference of caveolin-1 via lentiviral vector inhibits growth of hypopharyngeal squamous cell carcinoma FaDu cells in vitro and in vivo. Asian Pac J Cancer Prev 12: 397-401, 2011. 
10. Sun W, Yang Y, Xu C, Xie Y and Guo J: Roles of long noncoding RNAs in gastric cancer and their clinical applications. J Cancer Res ClinOncol 142: 2231-2237, 2016.

11. Chen S, Wu H, Lv N, Wang H, Wang Y, Tang Q, Shao H and Sun C: LncRNA CCAT2 predicts poor prognosis and regulates growth and metastasis in small cell lung cancer. Biomed Pharmacother 82: 583-588, 2016.

12. Ouyang S, Zhang P, Wang J, Huang Z and Liao L: Expression of long non-coding RNA colon cancer associated transcript 2 and its clinicopathologic significance in oral squamous cell carcinoma. Zhonghua Kou Qiang Yi XueZaZhi 51: 286-291, 2016 (In Chinese).

13. Huang S, Qing C, Huang Z and Zhu Y: The long non-coding RNA CCAT2 is up-regulated in ovarian cancer and associated with poor prognosis. Diagn Pathol 11: 49, 2016.

14. Zhou N, Si Z, Li T, Chen G, Zhang Z and Qi H: Long non-coding RNA CCAT2 functions as an oncogene in hepatocellular carcinoma, regulating cellular proliferation, migration and apoptosis. Oncol Lett 12: 132-138, 2016.

15. Redis RS, Vela LE, Lu W, Ferreira de Oliveira J, Ivan C, Rodriguez-Aguayo C, Adamoski D, Pasculli B, Taguchi A, Chen Y, et al: Allele-specific reprogramming of cancer metabolism by the long non-coding RNA CCAT2. Mol Cell 61: 520-534, 2016.

16. Redis RS and Calin GA: The interplay between $\ln R N A s$, SNPs, and protein complexes-what does it mean for cancer metabolism? Mol Cell Oncol 3: e1166308, 2016.

17. Barry KH, Moore LE, Sampson J, Yan L, Meyer A, Oler AJ, Chung CC, Wang Z, Yeager M, Amundadottir L and Berndt SI: DNA methylation levels at chromosome 8q24 in peripheral blood are associated with $8 \mathrm{q} 24$ cancer susceptibility loci. Cancer Prev Res (Phila) 7: 1282-1292, 2014.

18. Brisbin AG, Asmann YW, Song H, Tsai YY, Aakre JA, Yang P, Jenkins RB, Pharoah P, Schumacher F, Conti DV, et al: Meta-analysis of $8 \mathrm{q} 24$ for seven cancers reveals a locus between NOV and ENPP2 associated with cancer development. BMC Med Genet 12: 156, 2011.

19. Breyer JP, Dorset DC, Clark TA, Bradley KM, Wahlfors TA, McReynolds KM, Maynard WH, Chang SS, Cookson MS, Smith JA, et al: An expressed retrogene of the master embryonic stem cell gene POU5F1 is associated with prostate cancer susceptibility. Am J Hum Genet 94: 395-404, 2014.
20. Hayashi H, Arao T, Togashi Y, Kato H, Fujita Y, De Velasco MA, Kimura H, Matsumoto K, Tanaka K, Okamoto I, et al: The OCT4 pseudogene POU5F1B is amplified and promotes an aggressive phenotype in gastric cancer. Oncogene 34: 199-208, 2015.

21. Liu G, Pei F, Yang F, Li L, Amin AD, Liu S, Buchan JR and Cho WC: Role of autophagy and apoptosis in non-small-cell lung cancer. Int J Mol Sci 18: E367, 2017.

22. Zhou H, Yuan M, Yu Q, Zhou X, Min W and Gao D: Autophagy regulation and its role in gastric cancer and colorectal cancer. Cancer Biomark 17: 1-10, 2016.

23. Fu LL, Cheng Y and Liu B: Beclin-1: Autophagic regulator and therapeutic target in cancer. Int J Biochem Cell Biol 45: 921-924, 2013.

24. Yu ZY, Ding J, Yang XF and Zhang ZM: Significance of autophagy-related protein beclin-1 expression in gastric cancer: A Meta-analysis. Chin J Gen Surg 24: 1389-1395, 2015.

25. He Y, Zhao X, Subahan NR, Fan L, Gao J and Chen H: The prognostic value of autophagy-related markers beclin-1 and microtubule-associated protein light chain 3B in cancers: A systematic review and meta-analysis. Tumour Biol 35: 7317-7326, 2014.

26. Cao QH, Liu F, Yang ZL, Fu XH, Yang ZH, Liu Q, Wang L, Wan XB and Fan XJ: Prognostic value of autophagy related proteins ULK1, Beclin 1, ATG3, ATG5, ATG7, ATG9, ATG10, ATG12, LC3B and p62/SQSTM1 in gastric cancer. Am J Transl Res 8: 3831-3847, 2016

27. Polivka J Jr and Janku F: Molecular targets for cancer therapy in the PI3K/AKT/mTOR pathway. Pharmacol Ther 142: 164-175, 2014.

28. Liu M, Li CM, Chen ZF, Ji R, Guo QH, Li Q, Zhang HL and Zhou YN: Celecoxib regulates apoptosis and autophagy via the PI3K/Akt signaling pathway in SGC-7901 gastric cancer cells. Int J Mol Med 33: 1451-1458, 2014. 